\title{
Depletion of newly synthesized Argonaute1 impairs the RNAi response in Trypanosoma brucei
}

\author{
HUAFANG SHI, ${ }^{1}$ CHRISTIAN TSCHUDI, ${ }^{1,2}$ and ELISABETTA ULLU ${ }^{1,3}$ \\ ${ }^{1}$ Department of Internal Medicine, Yale University Medical School, New Haven, Connecticut 06536-0812, USA \\ ${ }^{2}$ Department of Epidemiology and Public Health, Yale University Medical School, New Haven, Connecticut 06536-0812, USA \\ ${ }^{3}$ Department of Cell Biology, Yale University Medical School, New Haven, Connecticut 06536-0812, USA
}

\begin{abstract}
In Trypanosoma brucei, Argonaute1 (TbAGO1) is an essential component of the RNA interference (RNAi) pathway. While characterizing a TbAGO1 conditional knockout cell line, we discovered that, upon blockage of TbAGO1 transcription, the RNAi response to transfected double-stranded RNA was severely inhibited, although there was no change in the TbAGO1 protein level. This observation suggested that steady-state TbAGO1 was not sufficient to fully support the RNAi response to transfected dsRNA and implicated newly synthesized Argonaute in this phenomenon. Indeed, a translational blockade of TbAGO1 mRNA with an antisense morpholino oligonucleotide resulted in inhibition of the RNAi response, even though the steady-state level of TbAGO1 remained unchanged during the time of the assay. Thus, we concluded that in $T$. brucei, newly synthesized TbAGO1 is required to support an efficient RNAi response. We speculate that newly processed siRNAs may be preferentially loaded onto newly synthesized TbAGO1, and this mechanism may contribute to the homeostasis of the RNAi pathway.
\end{abstract}

Keywords: RNA interference; Argonaute; conditional KO; trypanosome

\section{INTRODUCTION}

RNA interference (RNAi) is an evolutionarily conserved mechanism for sequence-specific gene silencing guided by double-stranded RNA (for review, see Tomari and Zamore 2005; Cerutti and Casas-Mollano 2006). Among the organisms in which RNAi has been demonstrated, the protozoan parasite Trypanosoma brucei represents one of the most ancient branches of the eukaryotic lineage (Ngo et al. 1998). Since its discovery in 1998 RNAi has become the method of choice used to study gene function in T. brucei and has provided researchers with a tool for forward genetic approaches (Morris et al. 2002), as well as for global analysis of gene function (Subramaniam et al. 2006). At the same time, mechanistic studies provided insight into the RNAi machinery and the biological function of RNAi. Double-stranded RNA (dsRNA) is processed into 24-26nucleotide (nt) small interfering RNAs (siRNAs) by a

Reprint requests to: Elisabetta Ullu, Department of Internal Medicine, Yale University Medical School, 295 Congress Avenue, New Haven, CT 06536-0812, USA; e-mail: elisabetta.ullu@yale.edu; fax: (203) 785-7329.

Article published online ahead of print. Article and publication date are at http://www.rnajournal.org/cgi/doi/10.1261/rna.474707. recently described unusual Dicer-like enzyme (TbDCL1) (Shi et al. 2006b). The signature motifs of Dicers and Dicerlike enzymes are two neighboring RNase III domains (RNase IIIa and RNase IIIb). In most members of this gene family the two RNase III domains are located toward the $\mathrm{C}$ terminus, in TbDCL1, one close to the $\mathrm{N}$ terminus, and the other centrally located. The second step in RNAi involves the endonucleolytic cleavage of the target mRNA by siRNAs, which is carried out by the RNA-induced silencing complex (RISC) (Hammond et al. 2000). One of the universal components of RISC is a member of the Argonaute protein family (Hammond et al. 2001). T. brucei is a useful model for RNAi because its genome has a single Argonaute protein (TbAGO1) (Durand-Dubief and Bastin 2003; Shi et al. 2004b), as compared to multicellular organisms, where this gene family has expanded to include up to 27 family members (Yigit et al. 2006). Characteristic of other Argonaute proteins, TbAGO1 contains a centrally located PAZ domain and a C-terminal Piwi domain. An additional noticeable feature of TbAGO1 is the presence at the $\mathrm{N}$ terminus of five direct repeats rich in arginine and glycine residues with a high abundance of RGG repeats. The trypanosome Argonaute protein is in a complex with siRNAs, and a proportion of this ribonucleoprotein particle 
is associated with polyribosomes (Djikeng et al. 2003; Shi et al. 2004b). Mechanistic studies are beginning to provide a better understanding of the molecular function of TbAGO1 and are consistent with TbAGO1 being the RNAi endonuclease (termed Slicer) (Shi et al. 2004c, 2006a). At present, no components of the RNAi pathway other than AGO1 and Dicer have been characterized in T. brucei, but it is highly likely that other RNAi-specific genes exist, such as, for instance, paralogs of double-stranded RNA-binding proteins, such as the Drosophila R2D2 (Liu et al. 2003) or the human TBRP (Chendrimada et al. 2005; Haase et al. 2005), which may be required to facilitate loading of siRNAs from TbDCL1 to TbAGO1.

To probe the biological role of RNAi in trypanosomes we (Shi et al. 2004b; Janzen et al. 2006), and others (DurandDubief and Bastin 2003), have knocked out both TbAGO1 alleles in different trypanosome strains and life-cycle stages. In all instances, viable trypanosomes were obtained. However, RNAi-deficient insect-form trypanosomes showed mild (Shi et al. 2004a) to severe (Durand-Dubief and Bastin 2003) growth defects. Genetic ablation of TbAGO1 disabled the RNAi pathway: the accumulation of transgeneor retroposon-derived siRNAs was drastically reduced, and target mRNAs were not degraded. In addition, these cells revealed an increased steady-state level of retroposon transcripts that was brought about by a combination of transcriptional activation of retroelements and increased stability of retroposon transcripts (Djikeng et al. 2001; Shi et al. 2004a,b). Finally, genetic ablation of TbAGO1 in a derivative of $T$. brucei 427 resulted in abnormalities in chromosome segregation (Durand-Dubief and Bastin 2003). Thus, the role of the RNAi pathway in trypanosomes may extend beyond a genome defense mechanism to keep at bay transcripts of retroelements, and may include a role in chromatin assembly, as it has been established for certain AGO-family members in a variety of organisms (Wassenegger 2005).

One aspect of RNAi that remains poorly explored is its possible regulation. In Arabidopsis, it is known that the synthesis of both Dcl1 (Xie et al. 2003) and AGO1 Slicer (Vaucheret et al. 2004) is regulated by a feedback mechanism involving gene-specific microRNAs (miRNAs). Furthermore, overexpression of Arabidopsis AGO1 was not tolerated (Vaucheret et al. 2004) and led to developmental defects, much like certain mutations in the Argonaute gene. In contrast, in Tetrahymena thermophila (Howard-Till and Yao 2006), expression of hairpin dsRNA was accompanied by up-regulation of transcripts of Dicer and Argonaute family genes, and possibly of the corresponding proteins, without deleterious effects on cells. More recently, overexpression of small hairpin RNAs (shRNAs) in mice resulted in toxicity (Grimm et al. 2006), suggesting that the endogenous miRNA-mediated pathway may be deregulated by the expression of large amounts of shRNAs. Although less than overwhelming, these observations pro- vide a hint that the RNAi pathway is regulated to ensure the proper execution of the various functions carried out by miRNAs and siRNAs.

To further analyze the function of the RNAi pathway in T. brucei and to examine whether this pathway may be regulated, we established a conditional TbAGO1 knockout cell line. In the course of the characterization of this cell line, we discovered that nascent synthesis of the TbAGO1 protein is required to sustain an RNAi response. We speculate that in trypanosomes, modulation of translation of TbAGO1 may contribute an important regulatory step in the RNAi pathway.

\section{RESULTS}

\section{Establishment of a conditional knockout of TbAGO1}

To provide further insight into the function and mechanism of RNAi in T. brucei, we established an experimental system in which the RNAi machinery can be turned on and off at will. In $T$. brucei regulated gene expression can be achieved using the system originally described by Wirtz and Clayton (1995), and subsequently modified to afford expression of highly toxic products (Biebinger et al. 1997; Wirtz et al. 1999). The strategy relies on a procyclin promoter, made responsive to the tetracycline (tet) repressor by addition of the tet operator, and the use of an appropriate cell line expressing the tet repressor and T7 RNA polymerase. One extension of this approach is the construction of inducible knockout (KO) strains (Clayton 1999), which we applied to the T. brucei Argonaute 1 gene. In the first step, one TbAGO1 allele was knocked out by replacement with a puromycin selectable marker in the insect-form cell line 29.13.6, which expresses the tet repressor and T7 RNA polymerase (Wirtz et al. 1999). Next, an ectopic TbAGO1 cassette under the control of the tet-inducible procyclin promoter was inserted at the ribosomal nontranscribed spacer. Finally, the second TbAGO1 allele was knocked out by replacement with a blasticidin selectable marker, while keeping the ectopic copy on by addition of tet to the selection medium. Thus, this strategy ensured that the RNAi pathway was always functional during the selection procedure. Several clonal cell lines were established and examined for regulation of TbAGO1 expression, and one cell line, termed $T b A G O 1 \mathrm{KO}_{c}$, was chosen for further analysis (data not shown).

Figure 1A shows that after tet removal, the TbAGO1 mRNA was undetectable within $1-2 \mathrm{~h}$, indicating that the expression of the ectopic $T b A G O 1$ gene was rapidly turned off. However, since the $3^{\prime}$-UTR of the ectopic TbAGO1 expression cassette was different from that present in the AGO1 gene and 3'-UTRs in trypanosomes can play a role in mRNA stability and turnover (Clayton 2002), it was important to compare the decay of $T b A G O 1 \mathrm{KO}_{\mathrm{c}}$ mRNA to that of AGO1 mRNA in wild-type cells under conditions 

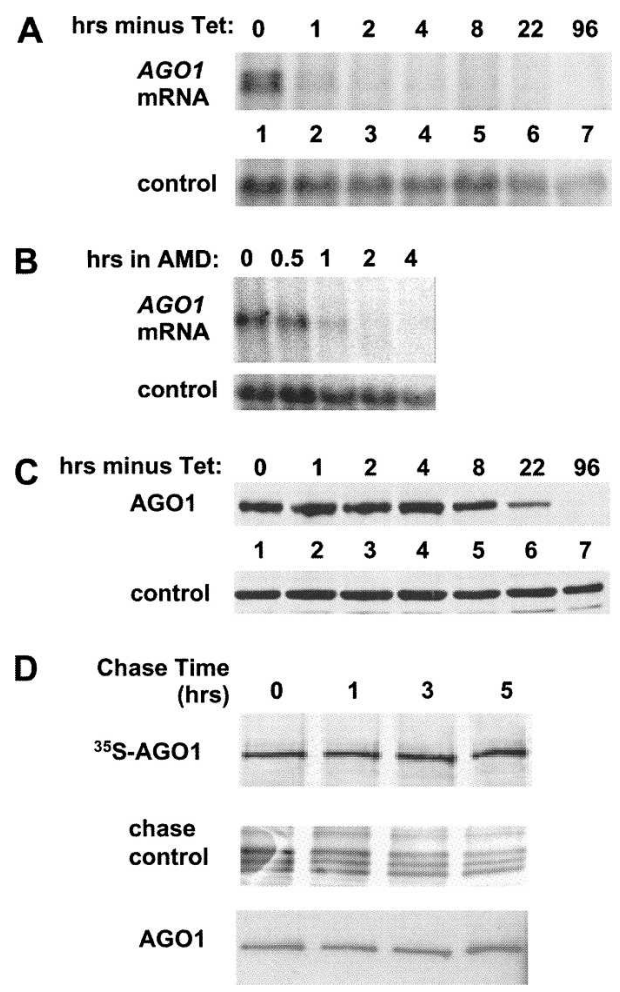

FIGURE 1. (A) Time course of TbAGO1 mRNA disappearance after removal of tet. $T b A G O 1 \mathrm{KO}_{c}$ cells were washed twice in medium and then put back in culture in tet-minus medium for the times indicated above each lane. RNA was extracted and analyzed by Northern blot using a TbAGO1 coding-region probe. Note that two hybridizing bands are seen in lane 1 ; they are derived from utilization of two alternate 3 -splice sites present upstream of the TbAGO1 coding region. Control: the membrane was stripped and rehybridized with a probe detecting the mitochondrial large ribosomal RNA. (B) Decay of TbAGO1 mRNA in wild-type trypanosomes. Wild-type trypanosomes were incubated with the transcription inhibitor actinomycin D (AMD) as previously described (Shi et al. 2004b). RNA samples were prepared at the times indicated above each lane and analyzed by Northern blotting with an AGO1 coding-region probe. Control: hybridization to the $18 \mathrm{~S}$ rRNA as a loading control. (C) Time course of the disappearance of TbAGO1 after tet removal. TbAGO1 $\mathrm{KO}_{\mathrm{c}}$ cells were washed and incubated in tet-free medium as described in the legend of $A$. Whole-cell extracts were fractionated on a $6 \%$ SDS-PAGE and processed for Western blotting with anti-AGO1 antibodies (Shi et al. 2004b). Control indicates a cross-reactive protein. (D) Endogenous TbAGO1 is a stable protein. A cell line expressing BB2-TAPtagged TbAGO1 (Shi et al. 2004b) was metabolically labeled with ${ }^{35} \mathrm{~S}$-methionine as described in Materials and Methods. After a 2-h pulse, the label was chased with an excess of unlabeled methionine, and cytoplasmic extracts were prepared at the times indicated above each lane. TbAGO1 was then immunoprecipitated with anti-BB2 antibodies, the immunoprecipitates were separated by SDS-PAGE, and the radioactive bands were detected by autoradiography. The panel chase control shows a group of bands from the total protein samples run in parallel to show that the chase was effective. As a control for the efficacy of the immunoprecipitation, the membrane shown in the upper panel was analyzed by Western blotting with the anti-BB2 antibody, which detects the total amount of AGO1 protein present in the immunoprecipitates. of transcriptional arrest. Thus, we incubated wild-type cells in the presence of the transcription inhibitor actinomycin $\mathrm{D}$ and monitored the $A G O 1$ mRNA over a period of $4 \mathrm{~h}$ by Northern blot analysis (Fig. 1B). Similar to the results obtained in the conditional KO strain, AGO1 mRNA was barely visible after $1 \mathrm{~h}$ and undetectable after $2 \mathrm{~h}$ of actinomycin $\mathrm{D}$ treatment. In contrast to the relatively rapid decay of the AGO1 mRNA, the ectopically expressed TbAGO1 protein was quite stable after tet removal: it began to decrease after $\sim 8 \mathrm{~h}$ and was undetectable after $96 \mathrm{~h}$ of growth (Fig. 1C). A comparable stability of the TbAGO1 protein was observed in pulse-chase experiments (Fig. 1D) in cells expressing an epitope-tagged and fully functional allele of TbAGO1 (BB2- TAP-tagged TbAGO1) (Shi et al. 2004b). From the data presented in Figure 1 and other experiments, we calculated that the half-life of TbAGO1 is $\sim 16 \mathrm{~h}$.

In the next set of experiments, we assessed whether there was a correlation between the level of expression of TbAGO1 and the extent of RNAi competency. TbAGO1$\mathrm{KO}_{\mathrm{c}}$ cells were grown in the absence of tet for $4 \mathrm{~d}$, which reduced the steady-state amount of TbAGO1 to undetectable levels (Fig. 2A, lane 6) and suppressed the ability of the cells to respond to challenge with $\alpha$-tubulin dsRNA (Fig. 2B, lane 6). RNAi competency was assessed (Fig. 2B) by measuring the extent of degradation of $\alpha$-tubulin mRNA in response to transfection with synthetic $\alpha$-tubulin dsRNA. Next, cells depleted for TbAGO1 were grown for $24 \mathrm{~h}$ in the presence of increasing concentrations of tet (Fig. 2A). Under these conditions, AGO1 became detectable at $0.1 \mu \mathrm{g} / \mathrm{mL}$ of tet (Fig. 2A, lane 3 ) and reached a maximum at $1.0 \mu \mathrm{g} / \mathrm{mL}$ (Fig. 2A, lane 2), concomitant with an increase of $\alpha$-tubulin mRNA degradation. Thus these results validated that the expression of TbAGO1 and the ability of the $T b A G O 1 \mathrm{KO}_{c}$ cells to respond to transfected dsRNA were conditional to the addition of tet to the growth medium. Finally, by Western blot analysis, we determined that even at the highest tet concentration tested, ectopic TbAGO1 was expressed at a level similar to that of TbAGO1 produced in wild-type cells (data not shown).

\section{Conditional inactivation of the ectopic $A G O 1$ allele results in an RNAi-deficient phenotype}

We have previously shown that in T. brucei, hallmarks of RNAi deficiency are up-regulation of retroposon transcripts and inhibition of accumulation of the corresponding siRNAs (Shi et al. 2004a,b; Janzen et al. 2006). To test whether the $T b A G O 1 \mathrm{KO}_{c}$ cells acquired this phenotype upon tet withdrawal, we examined the accumulation of transcripts derived from the retroposon Ingi (Fig. 3). As early as $1 \mathrm{~d}$ after tet removal, the abundance of Ingi transcripts began to increase as compared to cells grown in tet-containing media (Fig. 3, cf. lanes 1 and 2) and reached a maximum at $\sim 5 \mathrm{~d}$ (Fig. 3, lane 6). As expected, 


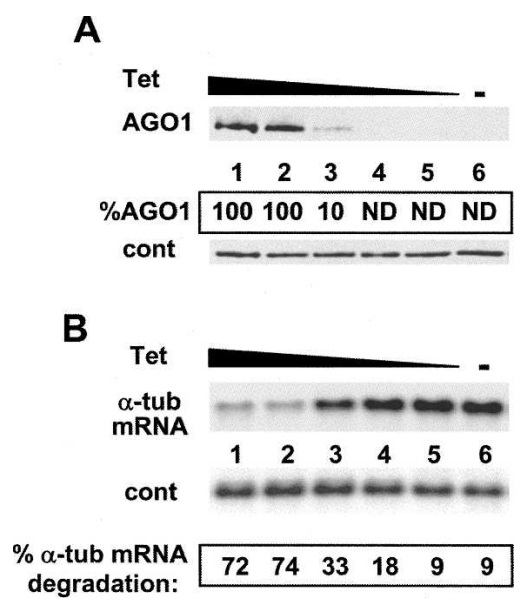

FIGURE 2. (A) Disappearance of AGO1 protein in response to decreasing tet concentrations. $T b A G O 1 \mathrm{KO}_{c}$ cells were grown in the absence of tet for $4 \mathrm{~d}$, and then incubated for $24 \mathrm{~h}$ with different tet concentrations (lanes 1-5) or without tet (lane 6). Cytoplasmic extracts were analyzed by Western blotting with an anti-AGO1 antiserum. Tet concentrations: (lane 1) $10 \mu \mathrm{g} / \mathrm{mL}$; (lane 2) $1.0 \mu \mathrm{g} / \mathrm{mL}$; (lane 3) $0.1 \mu \mathrm{g} / \mathrm{mL}$; (lane 4) $0.01 \mu \mathrm{g} / \mathrm{mL}$; (lane 5) $0.001 \mu \mathrm{g} / \mathrm{mL}$. (Cont) A cross-reactive protein. The amount of AGO1 was quantitated from the autoradiogram and is expressed as the percent of AGO1 expressed at the highest tet concentration. (ND) Not detectable. (B) The RNAi competency of $T b A G O 1 \mathrm{KO}_{c}$ cells decreased in response to incubation with decreasing amounts of tet. $T b A G O 1 \mathrm{KO}_{c}$ cells were grown using the same tet concentrations as described in A. After $24 \mathrm{~h}$, the cells were electroporated with $2 \mu \mathrm{g}$ of $\alpha$-tubulin dsRNA and then returned to the medium for $2 \mathrm{~h}$. Ten micrograms of total RNA was analyzed by Northern blotting using an $\alpha$-tubulin coding-region probe. The hybridized membranes were analyzed by PhosphorImaging, and the percent $\alpha$-tubulin mRNA degradation was calculated, after adjusting for loading differences, by taking the amount of $\alpha$-tubulin mRNA present at time 0 as $100 \%$.

the level of Ingi siRNAs significantly decreased after $3 \mathrm{~d}$ of growth in the absence of tet (Fig. 3B). Taken together, the results presented so far establish that the $T b A G O 1 \mathrm{KO}_{\mathrm{c}}$ cell line provides a system to fine tune AGO1 expression and as a consequence to modulate RNAi competency.

\section{A blockade of TbAGO1 transcription severely inhibits the RNAi response (before the TbAGO1 level declined)}

While exploring the timing of acquisition of RNAi deficiency by the retroposon transcript phenotype (Fig. 3), in preliminary experiments we observed that the RNAi response to transfected dsRNA began to decline soon after the TbAGO1 mRNA became undetectable (data not shown; Fig. 1A). To corroborate these initial observations, we grew TbAGO1 $\mathrm{KO}_{\mathrm{c}}$ cells in the presence and absence of tet for 2 $\mathrm{h}$, electroporated them with different amounts of $\alpha$-tubulin and paraflagellar rod (PFR) dsRNA, and $2 \mathrm{~h}$ later prepared RNA for Northern blot analysis (Fig. 4). Thus, the cells were grown in the absence of tet for a total of $4 \mathrm{~h}$. We chose to test RNAi efficiency at $2 \mathrm{~h}$ post-tet removal, since AGO1
mRNA was undetectable at this time point (Fig. 1A), whereas there was no noticeable change in the amount of AGO1 protein up to $4 \mathrm{~h}$ after tet removal (Fig. 1C). As expected, tubulin mRNA was efficiently targeted in cells transcribing the ectopic AGO1 allele (Fig. 4A, + tet). However, cells grown without tet showed an $\sim 50 \%$ reduction in their ability to degrade $\alpha$-tubulin mRNA at each dsRNA concentration tested (Fig. 4, - tet). In the case of the PFR mRNA, we observed a comparable reduction in RNAi efficiency, although targeting of this mRNA by homologous dsRNA was less efficient than in the case of $\alpha$ tubulin mRNA, as we observed previously (Ngo et al. 1998). By Western blotting (Fig. 4B), we confirmed that during the 4 -h time period of the assay there was no noticeable change in the steady-state amount TbAGO1. Thus, it appeared that RNAi competency declined due to a decrease in AGO1 mRNA levels, i.e., transcriptional blockage, and that the apparently unchanged steady-state levels of AGO1 protein were not sufficient to sustain an efficient RNAi response. Finally, Northern blot analysis (Fig. 4C) revealed that the level of Ingi transcripts did not detectably change during a 5-h incubation period in the absence of tet, suggesting that within this time halting AGO1 transcription did not result in a general inhibition of the RNAi pathway.

\section{Sequestering TbAGO1 mRNA away from translation inhibits the RNAi response}

Why was the RNAi competency reduced in $T b A G O 1 \mathrm{KO}_{c}$ cells after $4 \mathrm{~h}$ of incubation without tet, even if the AGO1

A

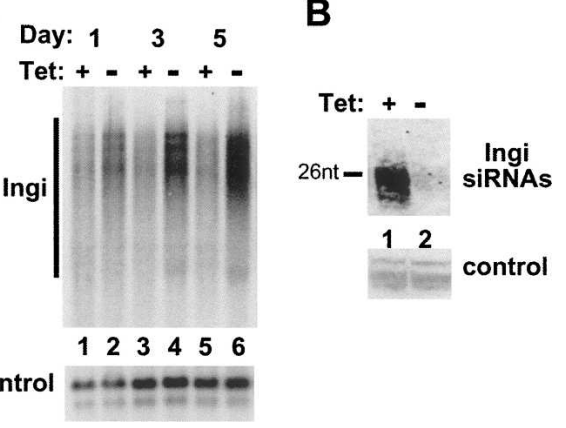

FIGURE 3. (A) Conditional $\mathrm{KO}$ of TbAGO1 results in up-regulation of large transcripts homologous to the Ingi retroposon transcripts. Total RNA was prepared from cells grown in the presence or absence of tet for the times indicated above each lane. Ingi transcripts were detected with an Ingi probe as described (Janzen et al. 2006). Control: hybridization to the calflagin mRNAs. (B) Conditional KO of TbAGO1 results in an inhibition of Ingi siRNA accumulation. TbAGO1 $\mathrm{KO}_{\mathrm{c}}$ cells were incubated in the presence $(+)$ or absence $(-)$ of tet for $24 \mathrm{~h}$. Total RNA was prepared and enriched for small RNAs as described previously (Shi et al. 2004b). The small RNAs were separated on a denaturing $15 \%$ polyacrylamide gel, electroblotted onto a nylon membrane, and hybridized with a sense radiolabeled riboprobe representing approximately the first $1000 \mathrm{nt}$ of the Ingi coding region. Control shows a group of cross-hybridizing bands. The position of a 26-nt DNA marker is shown by a bar on the side. 


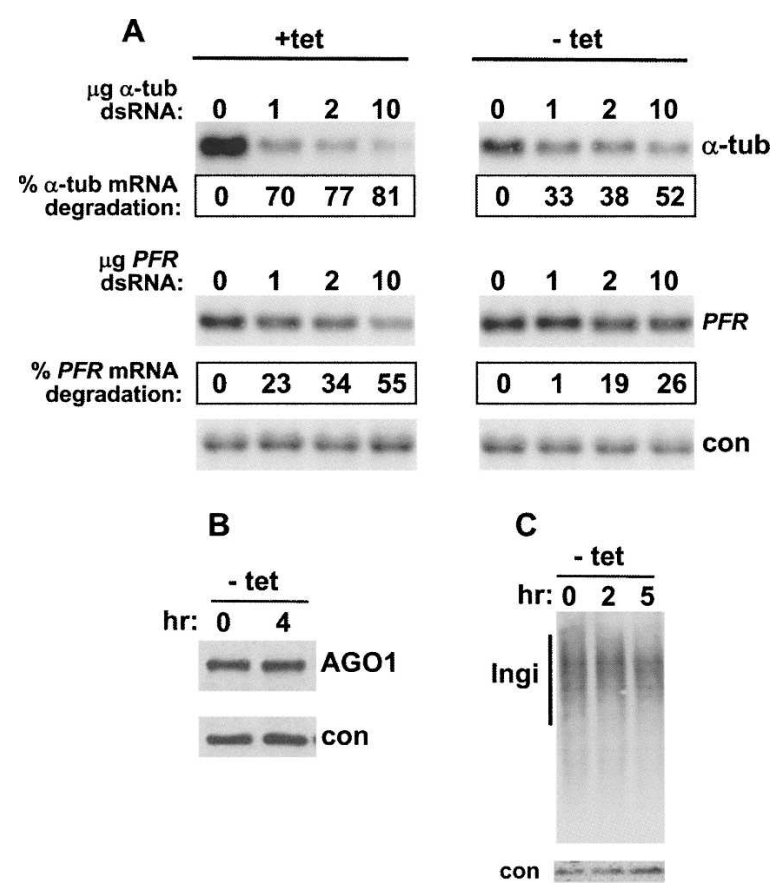

FIGURE 4. (A) Inhibition of TbAGO1KO $\mathrm{K}_{\mathrm{c}} \mathrm{RNAi}$ competency after $4 \mathrm{~h}$ of growth in the absence of tet. Cells were washed free of tet and incubated for $2 \mathrm{~h}$ without or with addition of tet. Next, cells were simultaneously transfected with different amounts of $\alpha$-tubulin and PFR dsRNA as indicated above each lane, and total RNA was isolated 2 $\mathrm{h}$ later. Ten micrograms of RNA was analyzed by Northern blotting with the following probes: a portion of the $\alpha$-tubulin coding region (upper panel); a portion of the PFR coding region (middle panel); a portion of the actin mRNA as a loading control. The percent mRNA degradation was calculated as described in the legend to Figure 2. (B) The steady-state amount of TbAGO1 does not change within $4 \mathrm{~h}$ from tet removal. Cells were washed free of tet and immediately lysed with SDS-PAGE (time 0 ) or grown for $2 \mathrm{~h}$, transfected with dsRNA, and then lysed $2 \mathrm{~h}$ later (time $4 \mathrm{~h}$ ). The presence of AGO1 was revealed by Western blotting with the anti-AGO1 antiserum. (Con) A crossreacting band used as a loading control. $(C)$ The steady-state level of Ingi transcripts does not change during $5 \mathrm{~h}$ of incubation in the absence of tet. Ten micrograms of total RNA extracted from cells immediately after tet removal (time 0 ) or after 2 or $5 \mathrm{~h}$ of incubation in the absence of tet was analyzed by Northern blotting with an Ingi coding-region probe. (Con) $18 \mathrm{~S}$ ribosomal RNA as a loading control.

protein was not limiting? We have shown that shutting off transcription of TbAGO1 by tet removal depleted cells of TbAGO1 mRNA, and, as a consequence, we predict that the Argonaute protein is no longer synthesized. Thus, one possible scenario for the observed reduction in RNAi competency is a requirement for newly synthesized AGO1 protein. To put this idea to the test, we employed a morpholino antisense oligonucleotide to sequester TbAGO1 mRNA from the translation apparatus. For this experiment, we chose a previously characterized trypanosome cell line, solely expressing TbAGO1 tagged at the $\mathrm{N}$ terminus with a BB2-TAP tag (Shi et al. 2004b), because it affords efficient immunoprecipitation of TbAGO1 using the $\mathrm{BB} 2$ monoclonal antibody and we have previously shown that the addition of the tag does not affect TbAGO1 function. Cells were transfected with a TbAGO1 antisense morpholino oligonucleotide complementary to positions $1-25$ of the coding region or with an oligonucleotide with the inverse sequence as a negative control. To verify that translation of TbAGO1 mRNA was, indeed, inhibited, $4 \mathrm{~h}$ after transfection the cells were metabolically labeled with ${ }^{35} \mathrm{~S}$-methionine for 2 or $4 \mathrm{~h}$, cytoplasmic extracts were prepared, and TbAGO1 was immunoprecipitated. Next, the immunoprecipitates were fractionated by SDS-PAGE and transferred to a nitrocellulose membrane, and the radiolabeled proteins were detected by autoradiography (Fig. $5 \mathrm{~A})$ and quantitated. By this analysis, in cells that received the morpholino antisense oligonucleotide, the synthesis of AGO1 was inhibited by $>80 \%$ compared to cells transfected with the inverse oligonucleotide. As a control for the efficiency of immunoprecipitation, the samples were analyzed by Western blotting to reveal the steady-state level of TbAGO1 present in the immunoprecipitates (Fig. 5A, bottom panel): Quantitation of the blot revealed that levels of immunoprecipitated TbAGO1 were comparable in each pair of samples. In conclusion, the antisense TbAGO1 morpholino oligonucleotide specifically inhibited the synthesis of TbAGO1.

To test whether inhibition of TbAGO1 translation by the morpholino oligonucleotide had any consequence on the efficiency of RNAi, we chose a cell line (pLEWFAT) that expresses $\alpha$-tubulin dsRNA under the control of the tetinducible PARP promoter (Shi et al. 2000). Thus, the dsRNA is produced from a transgene, and the cells need not to be transfected with synthetic dsRNA in order to monitor RNAi. After transfection with each of the two morpholino oligonucleotides, tet was added to the medium to activate expression of $\alpha$-tubulin dsRNA from the tetinducible transgene, and, at different times thereafter, the level of $\alpha$-tubulin mRNA was examined by Northern blotting (Fig. 5B). In cells that received no oligonucleotide or the control inverse oligonucleotide, the majority of $\alpha$-tubulin mRNA was degraded after $8 \mathrm{~h}$ of incubation. In contrast, transfection of the morpholino antisense oligonucleotide resulted in a severe attenuation of the RNAi response, with only $\sim 20 \%$ of the $\alpha$-tubulin mRNA having been degraded after $8 \mathrm{~h}$. Finally, we verified by Western blot analysis that over the period of the assay the steady-state level of TbAGO1 had not been detectably affected by the antisense morpholino oligonucleotide (Fig. 5C).

\section{DISCUSSION}

The most intriguing finding of our studies was that a few hours after blocking transcription of the TbAGO1 gene, we observed a substantial decrease in RNAi competency, as measured by transfection with dsRNA. Since the steadystate level of TbAGO1 did not change during this time period, we speculated that newly synthesized Argonaute 
A

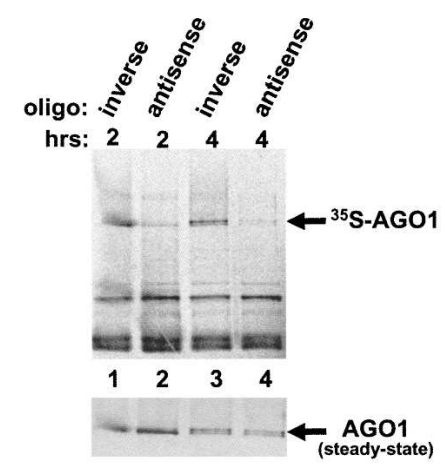

B

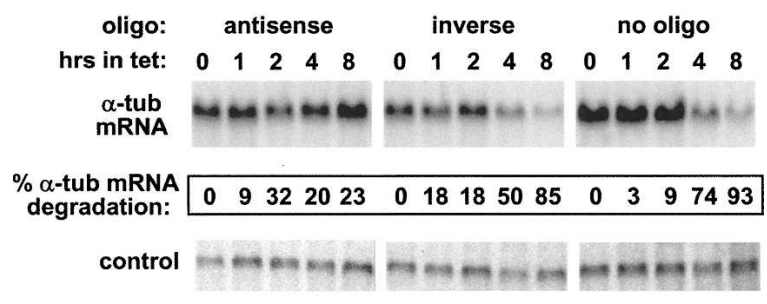

C

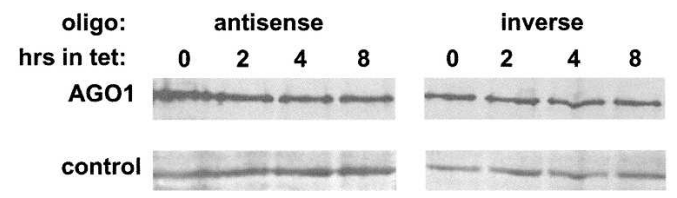

FIGURE 5. (A) Transfection of a morpholino antisense oligonucleotide inhibits accumulation of newly synthesized TbAGO1. Cells solely expressing BB2-TAP-tagged TbAGO1 were transfected with an AGO1 antisense morpholino oligonucleotide or with an oligonucleotide with the inverse sequence as a negative control (for details, see Materials and Methods). Four hours after transfection, the cells were metabolically labeled with ${ }^{35} \mathrm{~S}$-methionine for 2 or $4 \mathrm{~h}$, and cytoplasmic extracts were prepared and immunoprecipitated with anti-BB2 antibodies. The immunoprecipitates were separated by SDS-PAGE and the radioactive bands detected by autoradiography (upper panel). The same membrane was reacted with anti-AGO1 antibodies to verify the efficiency of immunoprecipitation (lower panel). (B) Transfection with the AGO1 antisense morpholino oligonucleotide inhibits degradation of $\alpha$-tubulin mRNA. A trypanosomes cell line conditionally expressing $\alpha$-tubulin dsRNA, pLEWFAT (Shi et al. 2000), was used for this analysis. Cells were transfected with the AGO1 antisense or inverse morpholino oligonucleotide, or mock-transfected (no oligo), and grown for the periods of time indicated above each lane in medium containing $10 \mu \mathrm{g} / \mathrm{mL}$ tet, which induces maximal synthesis of $\alpha$-tubulin dsRNA. At each time point, RNA was extracted and analyzed by Northern blotting with an $\alpha$-tubulin coding-region probe or with a control probe for actin mRNA. The percent $\alpha$-tubulin mRNA degradation was calculated as described in the legend to Figure 2. (B) The steady-state level of TbAGO1 does not significantly change upon transfection with morpholino oligonucleotides. pLEWFAT cells were transfected with the indicated morpholino oligonucleotides and grown in the presence of tet as described above. Samples were withdrawn at various intervals (indicated above each lane) and processed for Western blot analysis with anti-AGO1 antibodies. Control indicates a cross-reacting protein. protein was required to mount an efficient RNAi response. Indeed, blocking translation of TbAGO1 mRNA with an antisense morpholino oligonucleotide had a similar deleterious effect on RNAi efficiency. Thus, in trypanosomes there exist at least two pools of the Argonaute protein, namely, steady-state and newly synthesized TbAGO1, which differ in their ability to respond to transfected dsRNA. We know from previous experiments that steadystate AGO1 is loaded with endogenous siRNAs (Shi et al. 2004b), but most likely newly synthesized TbAGO1 is not yet complexed with siRNAs. Thus, one possible scenario is that newly processed siRNAs, as they are produced upon transfection of synthetic dsRNA, are preferentially loaded onto newly synthesized TbAGO1. Importantly, Gregory et al. (2005) showed that a preassembled ternary complex consisting of human Dicer, the dsRNA-binding protein TRBP, and AGO2 (i.e., the minimal RISC capable of recapitulating RNAi in vitro) is 10-fold more active when programmed with a Dicer substrate (dsRNA) than with a synthetic siRNA. This finding biochemically substantiated the coupling between dsRNA processing and loading of AGO2 Slicer with siRNAs. In this light, it may be that in T. brucei assembly of the so-called RISC loading complex (Preall and Sontheimer 2005, and references therein) occurs preferentially with newly synthesized TbAGO1. We can think of several possible mechanisms that would restrict the entry of steady-state TbAGO1 into the RISC loading complex. For instance, in vivo the steady-state trypanosome RISC complex may turn over very slowly, thus diminishing its ability to bind to newly processed siRNAs. Another possibility is that steady-state TbAGO1 may be compartmentalized away from TbDCL1 and other putative components of the RISC loading complex. However, at present there is no evidence for such a functional compartmentalization, although a proportion of TbAGO1 is associated with polyribosomes (Djikeng et al. 2003; Shi et al. 2004b). An attractive possibility, albeit at present only a speculative one, is that the conformation status of steadystate TbAGO1 particles may differ from that of newly synthesized TbAGO1 and not favor a productive interaction with the RISC loading complex. This idea implies that upon binding of an siRNA the structure of TbAGO1 may change. In support of this possibility, there is evidence from the crystal structure of prokaryotic Argonaute proteins (for review, see Tolia and Joshua-Tor 2007) and from molecular dynamics studies (Rashid et al. 2006) that the orientation of the PAZ domain is relatively flexible within these AGOfamily members, and this property may be crucial for loading AGO with an siRNA and/or for the AGO endonuclease activity. It is also possible that in vivo newly synthesized TbAGO1 may be held in a conformation suitable for interaction with the RISC loading complex by association with a chaperone. Indeed, earlier studies have uncovered an interaction between human AGO2 and Hsp90 (Tahbaz et al. 2004), a molecular chaperone with 
a selective number of client proteins, and have shown that inhibition of the ATPase function of Hsp90 results in inhibition of the interaction between recombinant human AGO2 and Dicer. By pull-down experiments of TAP-tagged TbAGO1, we have found that a proportion of TbHsp83 (the homolog of Hsp90) is selected (N. Chamond, unpubl.), suggesting that TbAGO1 may interact with this molecular chaperone. It remains to be seen whether it is newly synthesized TbAGO1 that preferentially interacts with TbHsp83 and whether this putative interaction is required for loading siRNAs into TbAGO1.

Understanding how the RNAi pathway is regulated is a central issue for the success of using this mechanism for therapeutic applications in human disease. The current evidence from plants, namely, that both AtDCL1 and AtAGO1 are regulated by specific miRNAs (Xie et al. 2003; Vaucheret et al. 2004) and that the expression of AtAGO1 and its companion miRNA is coregulated (Vaucheret et al. 2006), suggests that there is a regulatory network that ensures appropriate amounts of these proteins are produced. Indeed, we have noticed that in T. brucei the amount of TbAGO1 is strictly controlled, as a 10-fold overexpression of TbAGO1 mRNA does not result in any appreciable augmentation of the steady-state protein level (H. Shi, unpubl.). In contrast, the Dicer homolog TbDCL1 can be overexpressed (Shi et al. 2006b), indicating that the levels of DCL1 and AGO1 are independently regulated. The evidence presented here points to the possibility that control of TbAGO1 synthesis may play a role in the regulation of the RNAi pathway and this novel in vivo step may also be of importance in other systems.

\section{MATERIALS AND METHODS}

\section{Trypanosome cell lines}

Procyclic cells of strain T. brucei rhodesiense YTat1.1 were transfected as previously described (Shi et al. 2004b). For construction of the TbAGO1 conditional KO cell line, we used the cell line 29.13.6, which expresses the tet repressor and T7 RNA polymerase (Wirtz et al. 1999). First, one of the two TbAGO1 alleles was removed with an integration cassette encoding a puromycinresistance marker. Second, an ectopic copy of TbAGO1 was cloned in the expression vector pLEW100, which affords regulated expression from a procyclin promoter responsive to tet (Wirtz et al. 1999). This cassette contained $300 \mathrm{nt}$ upstream of the TbAGO1 gene and was followed at the $3^{\prime}$-end by the aldolase $3^{\prime}$-UTR. The cassette was inserted at the nontranscribed spacer at one of the rDNA loci. At this point, several clonal cell lines were examined for regulation of expression of the ectopic TbAGO1 copy, and one was chosen to proceed for the KO of the second TbAGO1 allele, which was carried out with a replacement cassette coding for the blasticidin selectable marker. While the cells were selected, tet was added to the medium to maintain the expression of TbAGO1.

\section{Antibodies, immunoprecipitations, and Western blot analysis}

BB2 monoclonal antibodies recognize an epitope tag corresponding to 10 amino acids from the major structural protein of the Saccharomyces cerevisiae Tyl virus-like particle (Bastin et al. 1996). For immunoprecipitation, anti-BB2 antibodies bound to protein G-Sepharose beads in NET-2 buffer $(150 \mathrm{mM} \mathrm{NaCl}, 50 \mathrm{mM}$ Tris at $\mathrm{pH} 7.5,0.05 \% \mathrm{NP}-40)$ were mixed with cell extracts and incubated for $4 \mathrm{~h}$ at $4^{\circ} \mathrm{C}$. The beads were then washed seven times with NET-2, and equivalent amounts of supernatants and beads were used for Western blot. Western blots were developed using ECL reagents (Amersham Biosciences) and exposed to Kodak XAR film. Metabolic labeling of trypanosomes with ${ }^{35}$ S-methionine was carried out essentially as described in Bangs et al. (1996) with minor modifications, namely, the labeling was carried out at a concentration of $2.5 \times 10^{7}$ cells/mL for up to $2 \mathrm{~h}$.

\section{Other procedures}

RNA extraction, dsRNA transfection, and Northern blot analysis were performed as described previously (Shi et al. 2004b). For blocking translation of TbAGO1 mRNA, the following morpholino oligonucleotides were used: antisense BB2-TAP-tagged TbAGO1, GGTATCCACGTTCCCAGTCAGACAT, complementary to positions $1-25$ of the coding region of the tagged gene, and an oligonucleotide with the inverse sequence, TACAGACT GACCCTTGCACCTATGG, as a negative control. Morpholino oligonucleotides $(500 \mu \mathrm{M}$ final concentration) were delivered to trypanosomes by electroporation.

\section{ACKNOWLEDGMENTS}

We are grateful to Kristin Patrick and Shobha Vasudevan for critical reading of the manuscript. This work was supported by Public Health Service grants to E.U. from NIAID.

Received January 17, 2007; accepted April 25, 2007.

\section{REFERENCES}

Bangs, J.D., Brouch, E.M., Ransom, D.M., and Roggy, J.L. 1996. A soluble secretory reporter system in Trypanosoma brucei. Studies on endoplasmic reticulum targeting. J. Biol. Chem. 271: 18387-18393.

Bastin, P., Bagherzadeh, Z., Matthews, K.R., and Gull, K. 1996. A novel epitope tag system to study protein targeting and organelle biogenesis in Trypanosoma brucei. Mol. Biochem. Parasitol. 77: 235-239.

Biebinger, S., Wirtz, L.E., Lorenz, P., and Clayton, C. 1997. Vectors for inducible expression of toxic gene products in bloodstream and procyclic Trypanosoma brucei. Mol. Biochem. Parasitol. 85: 99-112.

Cerutti, H. and Casas-Mollano, J.A. 2006. On the origin and functions of RNA-mediated silencing: From protists to man. Curr. Genet. 50: 81-99.

Chendrimada, T.P., Gregory, R.I., Kumaraswamy, E., Norman, J., Cooch, N., Nishikura, K., and Shiekhattar, R. 2005. TRBP recruits the Dicer complex to Ago2 for microRNA processing and gene silencing. Nature 436: 740-744.

Clayton, C.E. 1999. Genetic manipulation of kinetoplastida. Parasitol. Today 15: 372-378.

Clayton, C.E. 2002. Life without transcriptional control? From fly to man and back again. EMBO J. 21: 1881-1888.

Djikeng, A., Shi, H., Tschudi, C., and Ullu, E. 2001. RNA interference in Trypanosoma brucei: Cloning of small interfering RNAs 
provides evidence for retroposon-derived 24-26-nucleotide RNAs. RNA 7: 1522-1530.

Djikeng, A., Shi, H., Tschudi, C., Shen, S., and Ullu, E. 2003. An siRNA ribonucleoprotein is found associated with polyribosomes in Trypanosoma brucei. RNA 9: 802-808.

Durand-Dubief, M. and Bastin, P. 2003. TbAGO1, an Argonaute protein required for RNA interference is involved in mitosis and chromosome segregation in Trypanosoma brucei. BMC Biol. 1: 2.

Gregory, R.I., Chendrimada, T.P., Cooch, N., and Shiekhattar, R. 2005. Human RISC couples microRNA biogenesis and posttranscriptional gene silencing. Cell 123: 631-640.

Grimm, D., Streetz, K.L., Jopling, C.L., Storm, T.A., Pandey, K., Davis, C.R., Marion, P., Salazar, F., and Kay, M.A. 2006. Fatality in mice due to oversaturation of cellular microRNA/short hairpin RNA pathways. Nature 441: 537-541.

Haase, A.D., Jaskiewicz, L., Zhang, H., Laine, S., Sack, R., Gatignol, A., and Filipowicz, W. 2005. TRBP, a regulator of cellular PKR and HIV-1 virus expression, interacts with Dicer and functions in RNA silencing. EMBO Rep. 6: 961-967.

Hammond, S.M., Bernstein, E., Beach, D., and Hannon, G.J. 2000. An RNA-directed nuclease mediates post-transcriptional gene silencing in Drosophila cells. Nature 404: 293-296.

Hammond, S.M., Boettcher, S., Caudy, A.A., Kobayashi, R., and Hannon, G.J. 2001. Argonaute2, a link between genetic and biochemical analyses of RNAi. Science 293: 1146-1150.

Howard-Till, R.A. and Yao, M.C. 2006. Induction of gene silencing by hairpin RNA expression in Tetrahymena thermophila reveals a second small RNA pathway. Mol. Cell. Biol. 26: 8731-8742.

Janzen, C.J., van Deursen, F., Shi, H., Cross, G.A., Matthews, K.R., and Ullu, E. 2006. Expression site silencing and life-cycle progression appear normal in Argonaute1-deficient Trypanosoma brucei. Mol. Biochem. Parasitol. 149: 102-107.

Liu, Q., Rand, T.A., Kalidas, S., Du, F., Kim, H.E., Smith, D.P., and Wang, X. 2003. R2D2, a bridge between the initiation and effector steps of the Drosophila RNAi pathway. Science 301: 1921-1925.

Morris, J.C., Wang, Z., Drew, M.E., and Englund, P.T. 2002. Glycolysis modulates trypanosome glycoprotein expression as revealed by an RNAi library. EMBO J. 21: 4429-4438.

Ngo, H., Tschudi, C., Gull, K., and Ullu, E. 1998. Double-stranded RNA induces mRNA degradation in Trypanosoma brucei. Proc. Natl. Acad. Sci. 95: 14687-14692.

Preall, J.B. and Sontheimer, E.J. 2005. RNAi: RISC gets loaded. Cell 123: $543-545$.

Rashid, U.J., Paterok, D., Koglin, A., Gohlke, H., Piehler, J., and Chen, J.C. 2006. Structure of Aquifex aeolicus argonaute highlights conformational flexibility of the PAZ domain as a potential regulator of RNA-induced silencing complex function. J. Biol. Chem. 282: 13824-13832.

Shi, H., Djikeng, A., Mark, T., Wirtz, E., Tschudi, C., and Ullu, E. 2000. Genetic interference in Trypanosoma brucei by heritable and inducible double-stranded RNA. RNA 6: 1069-1076.

Shi, H., Chamond, N., Tschudi, C., and Ullu, E. 2004a. Selection and characterization of RNA interference-deficient trypanosomes impaired in target mRNA degradation. Eukaryot. Cell 3: 14451453.

Shi, H., Djikeng, A., Tschudi, C., and Ullu, E. 2004b. Argonaute protein in the early divergent eukaryote Trypanosoma brucei: Control of small interfering RNA accumulation and retroposon transcript abundance. Mol. Cell. Biol. 24: 420-427.

Shi, H., Ullu, E., and Tschudi, C. 2004c. Function of the trypanosome Argonaute 1 protein in RNA interference requires the $\mathrm{N}$-terminal RGG domain and arginine 735 in the Piwi domain. J. Biol. Chem. 279: 49889-49893.

Shi, H., Tschudi, C., and Ullu, E. 2006a. Functional replacement of Trypanosoma brucei Argonaute by the human slicer Argonaute2. RNA 12: 943-947.

Shi, H., Tschudi, C., and Ullu, E. 2006b. An unusual Dicer-like1 protein fuels the RNA interference pathway in Trypanosoma brucei. RNA 12: 2063-2072.

Subramaniam, C., Veazey, P., Redmond, S., Hayes-Sinclair, J., Chambers, E., Carrington, M., Gull, K., Matthews, K., Horn, D., and Field, M.C. 2006. Chromosome-wide analysis of gene function by RNA interference in the African trypanosome. Eukaryot. Cell 5: $1539-1549$.

Tahbaz, N., Kolb, F.A., Zhang, H., Jaronczyk, K., Filipowicz, W., and Hobman, T.C. 2004. Characterization of the interactions between mammalian PAZ PIWI domain proteins and Dicer. EMBO Rep. 5: 189-194.

Tolia, N.H. and Joshua-Tor, L. 2007. Slicer and the Argonautes. Nat. Chem. Biol. 3: 36-43.

Tomari, Y. and Zamore, P.D. 2005. Machines for RNAi. Genes \& Dev. 19: 517-529.

Vaucheret, H., Vazquez, F., Crete, P., and Bartel, D.P. 2004. The action of ARGONAUTE1 in the miRNA pathway and its regulation by the miRNA pathway are crucial for plant development. Genes \& Dev. 18: 1187-1197.

Vaucheret, H., Mallory, A.C., and Bartel, D.P. 2006. AGO1 homeostasis entails coexpression of MIR168 and AGO1 and preferential stabilization of miR168 by AGO1. Mol. Cell 22: 129-136.

Wassenegger, M. 2005. The role of the RNAi machinery in heterochromatin formation. Cell 122: 13-16.

Wirtz, L.E. and Clayton, C.E. 1995. Inducible gene expression in trypanosomes mediated by a prokaryotic repressor. Science 268: 1179-1183.

Wirtz, E., Leal, S., Ochatt, C., and Cross, G.A. 1999. A tightly regulated inducible expression system for conditional gene knock-outs and dominant-negative genetics in Trypanosoma brucei. Mol. Biochem. Parasitol. 99: 89-101.

Xie, Z., Kasschau, K.D., and Carrington, J.C. 2003. Negative feedback regulation of Dicer-Like1 in Arabidopsis by microRNA-guided mRNA degradation. Curr. Biol. 13: 784-789.

Yigit, E., Batista, P.J., Bei, Y., Pang, K.M., Chen, C.C., Tolia, N.H., Joshua-Tor, L., Mitani, S., Simard, M.J., and Mello, C.C. 2006. Analysis of the C. elegans Argonaute family reveals that distinct Argonautes act sequentially during RNAi. Cell 127: 747-757. 

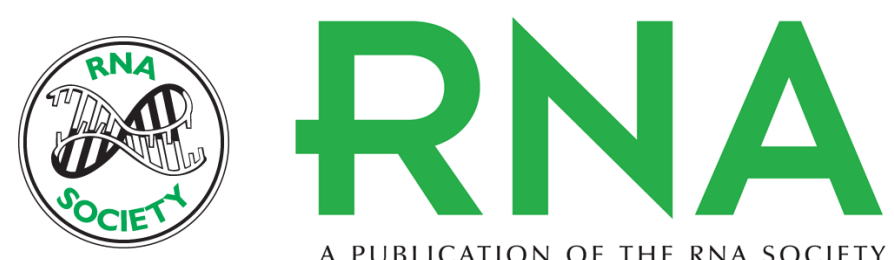

A PUBLICATION OF THE RNA SOCIETY

\section{Depletion of newly synthesized Argonaute1 impairs the RNAi response in Trypanosoma brucei}

Huafang Shi, Christian Tschudi and Elisabetta Ullu

RNA 2007 13: 1132-1139 originally published online May 25, 2007

Access the most recent version at doi:10.1261/rna.474707

$\begin{array}{ll}\text { References } & \begin{array}{l}\text { This article cites } 39 \text { articles, } 20 \text { of which can be accessed free at: } \\ \text { http://rnajournal.cshlp.org/content/13/7/1132.full.html\#ref-list-1 }\end{array}\end{array}$

License

Email Alerting Receive free email alerts when new articles cite this article - sign up in the box at the Service top right corner of the article or click here.

To subscribe to $R N A$ go to:

http://rnajournal.cshlp.org/subscriptions 